\title{
Research on the Spatial Spillover Effect of Transportation Infrastructure on Total Factor Productivity
}

\author{
Xuhang Bao \\ School of Economics and Management \\ Beijing Jiaotong University \\ Beijing, China
}

\begin{abstract}
Based on the panel data of 29 regions in China from 2001 to 2016, this paper used the spatial econometric model to empirically analyze the spatial spillover effects of railways, highways and general grade roads on total factor productivity. The research results show that during the study period, there is a significant spatial agglomeration phenomenon in China, both in terms of total factor productivity and various types of transportation infrastructure construction; all kinds of transportation infrastructure have promoted the improvement of total factor productivity in the region. The effect is mainly due to the spillover effect of other regions on the region, and the effect of the general grade road is the most significant, followed by the highway, the effect of railway is relatively small.
\end{abstract}

Keywords-spatial spillover effects; total factor productivity; transportation infrastructure construction; spatial agglomeration;

\section{INTRODUCTION}

Total factor productivity is an indicator of the efficiency of economic growth. It refers to the contribution of other factors to economic growth in the final output, except for tangible factors of production. The concept of total factor productivity has been widely concerned and studied since it has been proposed. The academic community generally considers that the growth rate of total factor productivity can reflect the degree of transition from the scale growth model determined by factor input to the innovation-driven economic growth model. In a certain sense, it means that the change in the growth rate of total factor productivity has a benchmarking significance for the transformation of a region's economic growth mode.

As a basic, leading and strategic industry in the national economy, the transportation industry has extensive and multilevel direct and indirect effects on the development of the national economy. On the one hand, transportation infrastructure can reduce transportation costs, improve regional accessibility, enhance inter-regional economic ties, promote the rational flow of various production factors, and promote the improvement of total factor productivity in the region. On the other hand, transportation infrastructure can also promote the economic development of the region to the surrounding areas; it will have a diffusion effect and jointly improve production efficiency. However, some scholars have suggested that under certain conditions, the transportation infrastructure will cause the capital and labor in the backward areas to be quickly lost to the more developed neighboring areas, thus hindering the improvement of total factor productivity in the region.

Does the transportation infrastructure have a spatial spillover effect on the development of regional total factor productivity? And is there any difference in the spatial spillover effects of different transportation infrastructures? In order to answer the above questions, this study took panel data of 29 regions in China from 2001 to 2016 as the research object, with railway density, highway density, and general grade road density as core variables, with human capital level, foreign investment dependence and trade dependence as control variables, and constructs a spatial panel econometric model to verify the spatial spillover effects of various transportation facilities on regional total factor productivity.

\section{LITERATURE REVIEW}

Currently, there are two different perspectives on the spatial spillover effects of transport infrastructure on total factor productivity. Some scholars consider that the transportation infrastructure has a significant positive spatial spillover effect. For example, Condeço-Melhorado et al. (2014) argued that transportation infrastructure is networked, so it can reduce the time and financial costs of transportation by enhancing inter-regional connectivity and convenience, resulting in positive spatial spillover effects[1]. However, this positive spatial spillover effect is heterogeneous between different transportation infrastructures, different regions and different research objects. Chen \& Haynes (2015) proposed that the positive spatial spillover effect of highways is significantly higher than that of railways and aviation through empirical analysis of the northeastern United States[2]; Hu \& Zhu (2015) verified the positive spatial spillover effect of transportation infrastructure on economic growth in central China is more significant by taking empirical analysis of China in the eastern and western regions[3]; Zhang \& Zhou (2012) compared the spatial spillover effects of transportation infrastructure between different industries, and considered the spatial spillover of transportation infrastructure for the secondary industry is greater than the spatial spillover of the tertiary industry, spatial spillover based on industrial structure is greater than spatial spillover based on market size[4]. 
Different from the research conclusions of the above scholars, some scholars consider that the spatial spillover effect of the traffic infrastructure is not significant, and even shows the negative spatial spillover effect. Holtz-Eakin, Douglas and Amy Ellen Schwartz (1995)used spatial econometrics to analyze panel data for eighteen states in the United States for 18 years and found that interstate highway capital does not have spillover effects on productivity[5]. Yu et al. (2013) argued that traffic infrastructure will have negative spatial spillover effects under the influence of unbalanced flow characteristics of production factors[6]; Ayuso et al. (2016) argued that improving transportation facilities would has a negative effect on the poor region, because they cannot benefit from the capital stock of neighboring regions like other richer regions[7].

In summary, the spillover effect of traffic infrastructure on total factor productivity has not been consistently reached in the academic world. In recent years, the growth rate of China's total factor productivity has been decreasing. At the same time, large-scale transportation infrastructure construction projects have been continuously completed. Therefore, taking China as the research object will be a useful attempt to study the spillover effects of transportation infrastructure on total factor productivity. Moreover, although scholars have recognized the heterogeneity between different transportation infrastructures, It's an extension of this study to investigate whether there is heterogeneity between the same transportation infrastructures, such as highways and non-highways.

\section{METHODOLOGY AND DATA}

\section{A. Spatial econometric model}

For spatial econometric model, Cliff and Ord first proposed an econometric model based on cross-section data in their book Spatial Autoregression[8]. Since then, Anselin, Elhorst and other scholars have extended the cross-section data to panel data[9][10]. The spatial panel metrology model can be divided into three types according to the different forms of spatial dependence: the Spatial Panel Lag Model (SPLM) which reflects the spatial dependence in the lag term, and the Spatial Panel Error Model (SPEM) which reflects the spatial dependence in the error term, as well as the Spatial Panel Dubin Model (SPDM) where spatial and dependent variables both have spatial dependencies. The expression of SPDM is shown in Equation (1):

$$
y_{i t}=\rho \sum_{j=1}^{N} w_{i j} y_{j t}+\beta x_{i t}+\sum_{j=1}^{N} \delta w_{i j} x_{j t}+\mu_{i}+v_{t}+\varepsilon_{i t}
$$

In the Equation (1), the observed values of the dependent variable and the independent variable of the individual $i$ in the $t$ period are $\mathrm{y}_{\mathrm{it}}$ and $\mathrm{x}_{\mathrm{it}} ; \rho$ and $\delta$ respectively represent the spatial overflow coefficient of the dependent variable and the independent variable; $\beta$ represents the independent parameter vector to be estimated; $\mathrm{w}_{\mathrm{ij}}$ represents the Space Weight Matrix, $\mu_{\mathrm{i}}$ is a spatial effect; $\mathrm{v}_{\mathrm{t}}$ is a time effect; $\varepsilon$ is a spatial error term, subject to independent distribution. In Equation (1), if $\delta=0$ and $\rho \neq 0$, the SPDM model can be simplified to the SPLM model. If $\delta+\rho \beta=0$, the SPDM model can be simplified to the SPEM model.
Based on the interrelationship of the above three models, scholars generally use the Spatial Dubin Model for analysis in model selection, and then test whether can use the spatial error model and the spatial autoregressive model. If both hypotheses $H_{0}: \delta=0$ and $H_{0}: \delta+\rho \beta=0$ are rejected, SPDM is selected; If there is at least one of the two hypotheses passes the test, then can make selection base on the LM (Lagrange multiplier) test result. In the existing research, scholars usually make the selection of SPEM and SPLM models through the following four LM test statistics, as shown in Equation (2)-(5):

$$
\begin{gathered}
L M-\text { Error }=\frac{\left(e^{\prime} W e / s^{2}\right)^{2}}{T} \sim \chi^{2}(1) \\
L M-\operatorname{Lag}=\frac{\left[e^{\prime} W y /\left(e^{\prime} e / N\right)\right]^{2}}{R} \sim \chi^{2}(1) \\
\text { Robust } L M-\text { Error }=\frac{\left(e^{\prime} W y / s^{2}-T R^{-1} e^{\prime} W e / s^{2}\right)^{2}}{\left(T-T^{2} R^{-1}\right)} \sim \chi^{2}(1) \\
\text { Robust } L M-\operatorname{Lag}=\frac{\left(e^{\prime} W y / s^{2}-e^{\prime} W e / s^{2}\right)^{2}}{(R-T)} \sim \chi^{2}(1) \\
\text { In Equation(2)-(5), , } s^{2}=e^{\prime} e / N \quad T=\operatorname{tr}\left(W^{2}+W^{\prime} W\right) \\
D=(W X \hat{\beta}) ' M(W X \hat{\beta}) e^{\prime} e / N+\operatorname{tr}\left(W^{2}+W^{\prime} W\right), \hat{\beta} \text { indicates the OLS }
\end{gathered}
$$
estimate of the model parameters when the model has no spatial correlation.

First, the residual is obtained by OLS regression, and calculate the LM-Error and LM-Lag quantities. If the LMError statistic is significant, the LM-Lag amount is not significant, then SPEM is used; if the LM-Error statistic is not significant and the LM-Lag amount is significant, SPLM is used; if neither is significant, the OLS result is maintained, and there is no spatial correlation; if both are significant, the Robust LM-Error and Robust LM-Lag statistic are further calculated. If the Robust LM-Error statistic is significant, then the SPEM model is selected; such as the Robust LM-Lag statistic significantly, choose SPLM. For the elastic coefficient of explanatory variables, LeSage and Pace (2009) pointed out that there is systematic deviation between the influence coefficient of the model estimation and the true partial regression coefficient, which means the two are not completely replaced, so it is necessary to use partial differential to decompose[11] , available from Equation (1):

$$
\begin{gathered}
\left(I_{n}-\rho W\right) y=X \beta+W X \delta+\ln \alpha+\varepsilon \\
y=\sum_{\mathrm{r}=1}^{k} S_{r}(W) x_{r}+V(W) \ln \alpha+V(W)+\varepsilon \\
S_{r}(W)=V(W)\left(I_{n} \beta_{r}+W \theta_{r}\right) \\
V(W)=\left(I_{n}-\rho W\right)^{-1}=I_{n}+\rho W+\rho^{2} W^{2}+\rho^{3} W^{3}+\ldots
\end{gathered}
$$

Converting Equation (7) to a matrix form yields: 


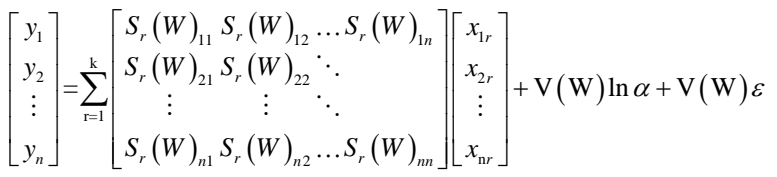

Partial derivative:

$$
\begin{gathered}
\frac{\partial y_{i}}{\partial x_{j r}}=S_{r}(W)_{i j}=\left(I_{n}-\rho W\right)^{-1} W_{i j} \delta_{r} \\
\frac{\partial y_{i}}{\partial x_{j r}}=S_{r}(W)_{i j}=\left(I_{n}-\rho W\right)^{-1} \beta_{r}
\end{gathered}
$$

Then, the matrix of the partial derivative of each dependent variable to the $\mathrm{r}^{\text {th }}$ independent variable can be expressed as:

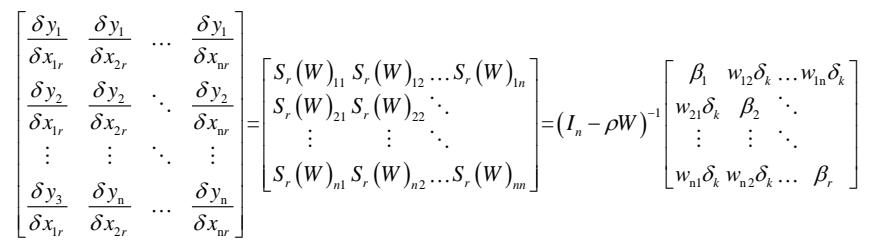

In Equation (13), the average value of each element on the diagonal is the direct effect, indicating the marginal effect of the independent variable relative to the dependent variable; the average value of each element on the off-diagonal line is the indirect effect, indicating the marginal effect of the independent variable spatial lag term relative to the dependent variable. The sum of direct effect and indirect effect is the total effect.

\section{B. Model Setting}

According to the discussion in the previous section, this study refers to the general practice of other scholars. Firstly, constructing the Spatial Panel Dubin Model (SPDM), and judging whether it is simplified to the Spatial Panel Lag Model (SPLM) or the Spatial Panel Error Model by testing several conditions of the model. (SPEM). The specific form of the model is shown in Equation (14):

$\ln \left(\mathrm{t} f \mathrm{p}_{i t}\right)=c+\lambda w \ln \left(t f p_{i t}\right)+\alpha^{T} \ln \left(\right.$ transport $\left._{i t}\right)+\beta^{T} \ln \left(C V_{i t}\right)$

$+f^{T} w \ln \left(\right.$ transport $\left._{i t}\right)+\gamma^{T} w \ln \left(C V_{i t}\right)+\varepsilon_{i t}$

$t f p_{i t}$ is the total factor productivity of the sample province $i$ in $t$ years.

$w$ is the Spatial Weight Matrix. This study uses spatially adjacent 0-1 matrices.

transport $_{i t}$ is the construction of the transportation infrastructure of the sample provinces in $t$ years, namely railways, highways and general grade roads.

$C V_{i t}$ is the control variable for the sample province $\mathrm{i}$ in $\mathrm{t}$ years, including trade dependence, foreign dependence (fdi), and human capital level (lk).

This study carried on the logarithm of above variables to eliminate heteroscedasticity and ensure data stability.

\section{Data and Variable Description}

This study took the provinces, municipalities and autonomous regions of mainland China as the research object. However, due to the serious lack of relevant data in Tibet, Hong Kong, Macao and Taiwan, and the fact that Chongqing was listed as a municipality until 1997, it is not suitable for separate calculation of the capital stock. The consistency and uniformity of the above areas were not included in the analysis framework. In summary, the main research object of this study is the sample of 29 regions in mainland China from 2001 to 2016. All the raw data are from the official website of China National Bureau of Statistics and China's provincial statistical bureaus, as well as the Annual China Statistical Yearbook, China Demographic Yearbook, China Financial Statistics Yearbook, etc.

$t f p$ is the dependent variable, and using random frontier production function method as the calculation method. The production function setting and variable processing method are consistent with the calculation methods of Binglian Liu and others[12], so it will not be repeated here.

Transport is the core variable. In this study, the railway density, highway density, and general grade road density (road) are used as indicators to reflect the level of transportation infrastructure construction.

Trade, fdi, and $l k$ are control variables. Among them: trade, investment and other economic activities are the main ways of spillover effects of knowledge and factors. This study used trade dependence (trade) and foreign investment (fdi) to indicate the level of regional economic and trade cooperation. Trade dependence (trade) is numerically equal to the ratio of total import and export volume to total GDP in each region. The foreign investment dependency (fdi) is numerically equal to the ratio of total foreign investment and total GDP in each region in the current year; if regional human capital has higher level, then the training cost that enterprises need to invest in the improvement of pure technical efficiency can be relatively less, and the advanced systems and methods can be better implemented. This paper selects the average education time of the population of each region to represent the human capital variable $(\mathrm{lk})$, which can be expressed as: Average years of education $=$ proportion of primary school education level $* 6+$ proportion of junior high school education level $* 9+$ high school The proportion of the degree of education is $* 12+$ the proportion of colleges and above education level $* 16$, and the base of the proportion is the total population of each region whose age is greater than or equal to 6 years old.

The descriptive statistics of the variables are shown in Table I:

TABLE I. DATA DESCRIPTION

\begin{tabular}{|c|c|c|c|}
\hline \multirow{2}{*}{ Variables } & \multicolumn{3}{|c|}{ Descriptive Index } \\
\cline { 2 - 4 } & Measurement & Mean & Standard Deviation \\
\hline tfp & - & 0.99 & 0.65 \\
\hline railway & $\mathrm{km} / 10,000$ pers & 208.11 & 176.19 \\
\hline road & $\mathrm{km} / 10,000$ pers & 5847.16 & 4271.22 \\
\hline hroad & $\mathrm{km} / 10,000$ pers & 200.80 & 230.21 \\
\hline trade & - & 0.32 & 0.39 \\
\hline fdi & - & 0.42 & 0.52 \\
\hline lk & year & 8.55 & 1.05 \\
\hline Observation & \multicolumn{3}{|c}{} \\
\hline
\end{tabular}




\section{EMPIRICAL FINDINGS}

\section{A. Spatial Correlation Test}

Before using the spatial model to measure the spatial effects of transportation infrastructure on total factor productivity, it is necessary to verify whether total factor productivity and the transportation infrastructure have spatial autocorrelation in geospatial. The spatial autocorrelation test is mainly divided into global and local spatial autocorrelation tests, which are different in the way of test method. The global spatial autocorrelation shows the average degree of convergence of observations with similar properties in the observed sample region; the local spatial autocorrelation reflects whether there are similar or different observations in the local space, and also reflects the degree of effect of local spatial on global spatial autocorrelation.

1) Global spatial autocorrelation test and Moran's I index

Academia usually uses Moran's I index (space autocorrelation index) to test Global space autocorrelation, this index is established by Moran. The expression of Moran's I index is shown in Equation (15):

$$
\text { Moran's } \mathrm{I}=\frac{N}{\sum_{i=1} \sum_{j=1} w_{i j}} \frac{\sum_{i=1} \sum_{j=1} W\left(X_{i}-\bar{X}\right)\left(X_{j}-\bar{X}\right)}{\sum_{i=1}\left(X_{i}-\bar{X}\right)^{2}}
$$

$N$ is the number of samples, $W$ is the spatial weight matrix, $X_{i}$ is the observed value of the $i^{\text {th }}$ region, $\bar{X}$ is the average of all observations.

The value range of the Moran's I index is $(-1,1)$. For example, if Moran's I index $<0$, it indicates that a variable in each region presents a spatial negative correlation, which appears as spatial dispersion; if Moran's I index $>0$, it indicates that a variable between each region presents a spatial positive correlation, which is presented as spatial agglomeration; if Moran's I index $=0$, it indicates that a variable between each region and the segment of the region are independent of each other. The absolute value of the Moran's I index reflects the spatial correlation between the sample observations. The absolute value of the Moran's I index is positively related to the spatial correlation. The global spatial autocorrelation test results of total factor productivity and transportation infrastructure indicators are shown in Table II.

TABLE II. MORAN'S I OF TFP AND TRANSPORTATION INFRASTRUCTURE INDICATORS IN CHINA 2001-2016

\begin{tabular}{|c|c|c|c|c|}
\hline \multirow{2}{*}{ Year } & \multicolumn{4}{|c|}{ Moran's I Calculation Result } \\
\cline { 2 - 5 } & $\boldsymbol{t} \boldsymbol{f} \boldsymbol{p}$ & railway & road & hroad \\
\hline 2001 & $0.263^{* * *}$ & $0.320^{* * *}$ & $0.369^{* * *}$ & $0.394^{* * *}$ \\
\hline 2002 & $0.246^{* * *}$ & $0.332^{* * *}$ & $0.360^{* * *}$ & $0.341^{* * *}$ \\
\hline 2003 & $0.235^{* * *}$ & $0.337^{* * *}$ & $0.365^{* * *}$ & $0.337^{* * *}$ \\
\hline 2004 & $0.259^{* * *}$ & $0.343^{* * *}$ & $0.366^{* * *}$ & $0.238^{* * *}$ \\
\hline 2005 & $0.237^{* * *}$ & $0.334^{* * *}$ & $0.367^{* * *}$ & $0.240^{* * *}$ \\
\hline 2006 & $0.268^{* * *}$ & $0.325^{* * *}$ & $0.508^{* * *}$ & $0.268^{* * *}$ \\
\hline 2007 & $0.256^{* * *}$ & $0.318^{* * *}$ & $0.511^{* * *}$ & $0.269^{* * *}$ \\
\hline 2008 & $0.224^{* * *}$ & $0.344^{* * *}$ & $0.527^{* * *}$ & $0.288^{* * *}$ \\
\hline 2009 & $0.134^{*}$ & $0.331^{* * *}$ & $0.530^{* * *}$ & $0.255^{* * *}$ \\
\hline 2010 & $0.139^{*}$ & $0.289^{* * *}$ & $0.534^{* * *}$ & $0.262^{* * *}$ \\
\hline 2011 & $0.109^{*}$ & $0.297^{* * *}$ & $0.540^{* * *}$ & $0.248^{* * *}$ \\
\hline
\end{tabular}

\begin{tabular}{|c|c|c|c|c|}
\hline \multicolumn{5}{|c|}{ Cont. to TABLE II. } \\
\hline 2012 & $0.151^{* *}$ & $0.307^{* * *}$ & $0.547^{* * *}$ & $0.256^{* * *}$ \\
\hline 2013 & $0.298^{* * *}$ & $0.329 * * *$ & $0.554^{* * *}$ & $0.260^{* * *}$ \\
\hline 2014 & $0.145^{* *}$ & $0.329 * * *$ & $0.544^{* * *}$ & $0.261^{* * *}$ \\
\hline 2015 & $0.227^{* * *}$ & $0.348^{* * *}$ & $0.547^{* * *}$ & $0.260^{* * *}$ \\
\hline 2016 & $0.123^{*}$ & $0.344^{* * *}$ & $0.564 * * *$ & $0.260^{* * *}$ \\
\hline
\end{tabular}

$*, * *, * * *$ means passing the significance test at $10 \%, 5 \%$ and $1 \%$ levels

As shown in Table II, the global Moran's I index values for total factor productivity, railway density, highway density, and general grade road density during the study period are all positive. Except that total factor productivity is significant at $10 \%$ in individual years, the indicators in most of the years have passed the significance test at the $1 \%$ level, indicating that there is significant spatial dependence on the total factor productivity or the transportation infrastructure in the provinces, and the space dependence of the general grade roads is the strongest, followed by railways, highways rank the third, and total factor productivity is relatively weakest. From the time trend, the spatial dependence of total factor productivity shows a trend of " $U$ " shape change trend, the railway has no significant one-way change trend, the spatial dependence of highways decreases year by year, while the space dependence of general grade roads is enhanced year by year.

\section{2) Local space autocorrelation test and local Moran'I} scatter plots

Local space autocorrelation test, generally using local Moran I scatter plots for testing. It is shown in Equation (16).

$$
\text { Local Moral } I=\frac{N\left(X_{i}-\bar{X}\right) \sum_{j=1} W\left(X_{j}-\bar{X}\right)}{\sum_{i=1}\left(X_{i}-\bar{X}\right)^{2}}=\frac{\left(X_{i}-\bar{X}\right) \sum_{j=1} W\left(X_{j}-\bar{X}\right)}{S^{2}}
$$

$N$ represents the number of samples, $W$ represents the spatial weight matrix, $X_{i}$ is the observation of the $i^{\text {th }}$ region, $\bar{X}$ is the average of all observations, and $S^{2}$ represents the variance of the observations.

The local Moran's I scatter plot shows the relationship between the $X$ variable and the spatial lag term $W X$ by means of a two-dimensional map, which is divided into four quadrants, so it can describe the type of local spatial aggregation. Quadrant 1 is "high-high", the region with higher observations in the sample is surrounded by regions that are also higher observations; quadrant 2 is "low-high", the region with lower observations in the sample is surrounded by areas of higher observation; quadrant 3 is "low- low", the region of lower observations in the sample is surrounded by regions that are also lower observations; quadrant 4 is "high-low", the region with higher observations in the sample is surrounded by regions of lower observation. Both the Moran's I index and the local Moran's I scatter plot are approximated to follow a normal distribution, so that the existence of spatial or local autocorrelation can be tested by establishing a standardized Z statistic. This study measured the local Moran's I values of the four indicators in 2016. The scatter plot is shown in Fig. 1.The four pictures in Fig. 1 is the local Moran's I index scatter plot for tfp, railway, road, and hroad in 2016. From the Fig. 1, it can be seen that the spatial agglomeration effect of the general grade road is the most significant, and most of them are 
concentrated in quadrant 1 or 3.That is, mainly in high-high, low-low agglomeration mode; although spatial agglomeration of total factor productivity is not more significant than other variables, mainly in high-high, low-low agglomeration mode; railways and highways are mainly in low-low agglomeration pattern, and the agglomeration of the high-high mode is near to the origin.

\section{B. Estimation Results and Discussion}

The spatial autocorrelation test shows that the total factor productivity and the level of transportation infrastructure construction have significant spatial dependence characteristics, and the spatial elements cannot be ignored when studying the relationship between the two. Therefore, the application of the spatial panel model can avoid the bias of the regression estimation results due to the existence of spatial effects. For the inspection and identification of the spatial panel measurement model, it can be judged by WALD test and LR test. The test results which using railways as transportation infrastructure variables are shown in Table III.

As shown in Table III, both the WALD test and the LR test reject the null hypothesis, it means there are spatial lag terms as well as spatial error terms, so the Spatial Dubin Model (SDM) should be used for analysis. The test results which using highways and general grade roads as traffic infrastructure variables are similar. The Spatial Dubin Model (SDM) is more suitable than the Spatial Lag Model (SLM) and Spatial Error Model (SEM). The estimated results of railways, highways, and general grade roads are shown in Table IV, Table V, and Table VI.

TABLE III. WALD STATISTICS AND LR STATISTICS

\begin{tabular}{|c|c|c|}
\hline \multirow{2}{*}{ Statistical Indicator } & \multicolumn{2}{|c|}{ Test Result } \\
\cline { 2 - 3 } & Estimated Value & P-Value \\
\hline WALD_SPATIAL_LAG & $29.749 * * *$ & 0.009 \\
\hline LR_SPATIAL_LAG & $38.283^{* * *}$ & 0.001 \\
\hline WALD_SPATIAL_ERROR & $38.782^{* * *}$ & 0.001 \\
\hline LR_SPATIAL_ERROR & $36.914^{* * *}$ & 0.002 \\
\hline HAUSMAN & $98.137^{* * *}$ & 0.000 \\
\hline
\end{tabular}
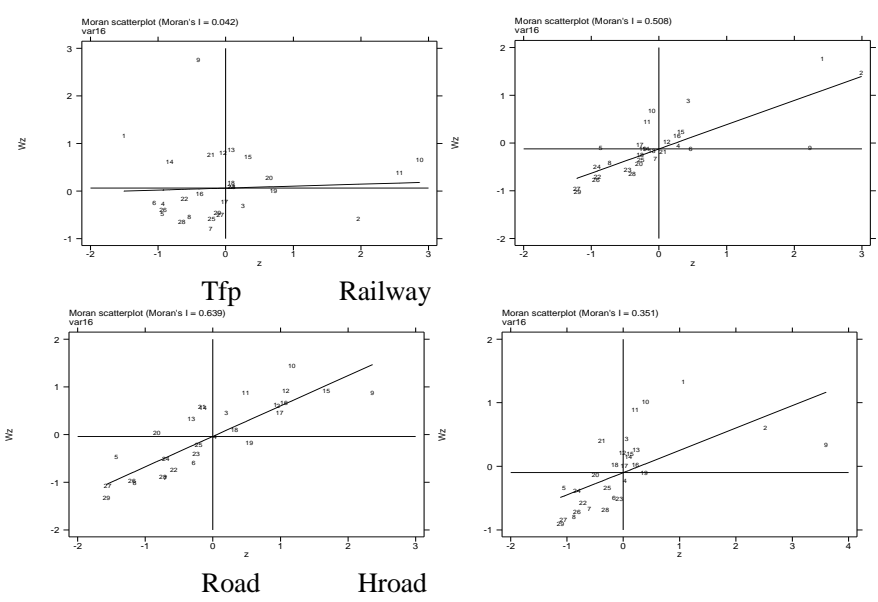

Fig. 1. Moran’s I scatter plot
TABLE IV. ESTIMATION RESULTS OF SDM

\begin{tabular}{|c|c|c|c|}
\hline \multirow{2}{*}{ Variable } & \multicolumn{3}{|c|}{ Estimation Results } \\
\hline & Total Effect & Direct Effect & Indirect Effect \\
\hline railway & $\begin{array}{c}0.0085^{* * *} \\
(0.003)\end{array}$ & $\begin{array}{l}0.0012 \\
(0.002)\end{array}$ & $\begin{array}{c}0.0073^{* * *} \\
(0.0028)\end{array}$ \\
\hline trade & $\begin{array}{c}0.0234^{* * * *} \\
(0.008)\end{array}$ & $\begin{array}{c}0.0103^{* * * *} \\
(0.002)\end{array}$ & $\begin{array}{l}0.0131^{*} \\
(0.0072)\end{array}$ \\
\hline fdi & $\begin{array}{l}0.0023 \\
(0.009)\end{array}$ & $\begin{array}{l}0.0031^{* *} \\
(0.0015)\end{array}$ & $\begin{array}{l}-0.0008 \\
(0.0070)\end{array}$ \\
\hline $\mathrm{lk}$ & $\begin{array}{l}0.0006 \\
(0.010)\end{array}$ & $\begin{array}{l}0.0012^{*} \\
(0.0007)\end{array}$ & $\begin{array}{l}-0.0006 \\
(0.0004)\end{array}$ \\
\hline railway*trade & $\begin{array}{c}0.0002^{*} \\
(0.00012)\end{array}$ & $\begin{array}{l}0.0001^{* *} \\
(0.00005)\end{array}$ & $\begin{array}{l}0.0001 \\
(0.0001)\end{array}$ \\
\hline railway*fdi & $\begin{array}{r}-0.0007 \\
(0.002)\end{array}$ & $\begin{array}{c}0.0001^{*} \\
(0.000055)\end{array}$ & $\begin{array}{l}-0.0008 \\
(0.0014)\end{array}$ \\
\hline railway*lk & $\begin{array}{l}0.0013 \\
(0.018)\end{array}$ & $\begin{array}{l}0.0012 \\
(0.006)\end{array}$ & $\begin{array}{r}0.0001 \\
(0.05)\end{array}$ \\
\hline rho & $\begin{array}{c}0.5088^{* * * *} \\
(12.11)\end{array}$ & Ajusted-R ${ }^{2}$ & 0.4387 \\
\hline
\end{tabular}

TABLE V. ESTIMATION RESULTS OF SDM

\begin{tabular}{|c|c|c|c|}
\hline \multirow{2}{*}{ Variable } & \multicolumn{3}{|c|}{ Estimation Results } \\
\hline & Total Effect & Direct Effect & Indirect Effect \\
\hline hroad & $\begin{array}{c}0.0090 * * * \\
(0.0018)\end{array}$ & $\begin{array}{c}0.0020 \\
(0.0013)\end{array}$ & $\begin{array}{c}0.0070 * * * \\
(0.0018)\end{array}$ \\
\hline trade & $\begin{array}{c}0.0040 \\
(0.0083)\end{array}$ & $\begin{array}{c}0.0076 * * * \\
(0.0024)\end{array}$ & $\begin{array}{l}-0.0036 \\
(0.0069)\end{array}$ \\
\hline fdi & $\begin{array}{c}0.0083 \\
(0.0169)\end{array}$ & $\begin{array}{l}0.0021^{*} \\
(0.0012)\end{array}$ & $\begin{array}{c}0.0062 \\
(0.0076)\end{array}$ \\
\hline $\mathrm{lk}$ & $\begin{array}{c}0.0103 \\
(0.0116)\end{array}$ & $\begin{array}{c}0.0039^{*} \\
(0.002)\end{array}$ & $\begin{array}{c}0.0064 \\
(0.0012)\end{array}$ \\
\hline hroad*trade & $\begin{array}{l}0.0002^{*} \\
(0.00011)\end{array}$ & $\begin{array}{c}0.0003^{*} \\
(0.00016)\end{array}$ & $\begin{array}{r}-0.0001 \\
(-0.30)\end{array}$ \\
\hline hroad*fdi & $\begin{array}{c}0.0005^{*} \\
(0.00026)\end{array}$ & $\begin{array}{l}0.0002^{* *} \\
(0.00009)\end{array}$ & $\begin{array}{c}0.0003 \\
(0.0012)\end{array}$ \\
\hline hroad*lk & $\begin{array}{l}-0.0017 \\
(0.0013)\end{array}$ & $\begin{array}{c}0.0001 \\
(0.0007)\end{array}$ & $\begin{array}{l}-0.0018 \\
(0.0011)\end{array}$ \\
\hline rho & $\begin{array}{c}0.4596 * * * \\
(0.045)\end{array}$ & Ajusted-R ${ }^{2}$ & 0.3997 \\
\hline
\end{tabular}

TABLE VI. ESTIMATION RESULTS OF SDM

\begin{tabular}{|c|c|c|c|}
\hline \multirow{2}{*}{ Variable } & \multicolumn{3}{|c|}{ Estimation Results } \\
\hline & Total Effect & Direct Effect & Indirect Effect \\
\hline road & $\begin{array}{c}0.0097^{* * * *} \\
(0.0031)\end{array}$ & $\begin{array}{l}-0.0009 \\
(0.0017)\end{array}$ & $\begin{array}{c}0.0105^{* * *} \\
(0.0030)\end{array}$ \\
\hline trade & $\begin{array}{c}0.0106 \\
(0.0078)\end{array}$ & $\begin{array}{c}0.0096^{* * *} \\
(0.0022)\end{array}$ & $\begin{array}{c}0.0010 \\
(0.0067)\end{array}$ \\
\hline fdi & $\begin{array}{c}0.0031 \\
(0.0086)\end{array}$ & $\begin{array}{l}-0.0026 \\
(0.0016)\end{array}$ & $\begin{array}{c}0.0057 \\
(0.0068)\end{array}$ \\
\hline $\mathrm{lk}$ & $\begin{array}{c}0.0119 \\
(0.0118)\end{array}$ & $\begin{array}{c}0.0046 \\
(0.0060)\end{array}$ & $\begin{array}{c}0.0073 \\
(0.0177)\end{array}$ \\
\hline road*trade & $\begin{array}{l}0.0010^{*} \\
(0.0005)\end{array}$ & $\begin{array}{c}0.0003^{*} \\
(0.00016) \\
\end{array}$ & $\begin{array}{c}0.0007 \\
(0.0008) \\
\end{array}$ \\
\hline road*fdi & $\begin{array}{c}0.0008 \\
(0.0007)\end{array}$ & $\begin{array}{c}0.0003^{*} \\
(0.00017)\end{array}$ & $\begin{array}{c}0.0005 \\
(0.0007)\end{array}$ \\
\hline road*lk & $\begin{array}{l}0.0031^{*} \\
(0.0017) \\
\end{array}$ & $\begin{array}{l}0.0010^{*} \\
(0.0005) \\
\end{array}$ & $\begin{array}{c}0.0021 \\
(0.0014) \\
\end{array}$ \\
\hline rho & $\begin{array}{c}0.4703^{* * * *} \\
(0.044)\end{array}$ & Ajusted-R ${ }^{2}$ & 0.3841 \\
\hline
\end{tabular}

The estimation results show that each transportation infrastructure has a certain promotion effect on the improvement of regional total factor productivity, but all of 
them are mainly indirect effects, and the direct effects are not significant. Comparing the coefficient of action of various transportation infrastructures, the promotion effect of general grade roads is the most obvious, the highway is the second, and the railway is the weakest. This may because the average transportation distance of the general grade road is relatively short. Whether it is the exchange and diffusion of knowledge, or the flow of production factors, there is a significant reversal relationship with the distance.

Among the control variables, the trade dependence on the improvement of total factor productivity is obvious. When the railway is used as the transportation infrastructure variable, the total effect, the indirect effect and the direct effect all pass the significant test; when the highway and the general grade road are In the case of transportation infrastructure variables, the indirect effects did not pass the significance test. Foreign investment dependence and the level of human capital are in a similar situation, when the railway and highway are the transportation infrastructure variables; both have a certain positive direct effect. When the general grade road is used as the transportation infrastructure variable, the direct effects, indirect effects, and total effects are not significant.

For the intersection of different transportation infrastructures and various control variables, as discussed in this chapter, the transportation infrastructure does have the positive effect on regional economic and trade cooperation as well as the optimization of production factor structure on regional total factor productivity, the positive effect of general grade roads is relatively stronger, followed by highways, railways are relatively weakest, and the path of positive influence is mainly to promote regional import and export trade, followed by promoting foreign direct investment. The positive effect on the improvement of human capital level is only available on general grade roads.

\section{CONCLUSION}

Based on the panel data of 29 regions in China from 2001 to 2016, this study took the railway density, highway density, and general grade road density as the core variables, and used the human capital level, foreign capital dependence and trade dependence as the control variable, then verified the spatial spillover effects of various transportation facilities on the total factor productivity of the region by constructing Spatial Panel Econometric Model, and obtained the following estimation results:

- During the study period, there is a significant spatial agglomeration phenomenon in both total factor productivity and the construction of various traffic technology facilities. The distribution of general grade roads is relatively average, and the other three indicators are mostly weak-weak clusters.

- All transportation infrastructures have certain effect on promoting the improvement of total factor productivity in the region, but they are mainly based on the spillover effects of other regions on the region, and the effect of general grade roads is most significant, followed by highways, the effect of railways is relatively small.
- The positive effect of general grade roads is most significant in all transportation infrastructures, and the positive effect of railways is relatively weak, which may be related to the average transport distance of different transport infrastructures. General grade roads are more used for short-distance transportation, connecting the inter-regional space is relatively short, facilitating the diffusion of knowledge and the flow of production factors.

The conclusion of the study indicates that:

- The spatial spillover effect of China's transportation infrastructure caused by different modes of transportation through promoting the flow of factors needs to be fully considered. Unreasonable integrated transportation system may cause the excessive accumulation of various factors such as human capital in central cities and the loss of high-level labor and other factors in the surrounding areas. As a result, the overall factor productivity of the whole region will be slowed or even reduced.

- China's transportation infrastructure construction should pay attention to the construction of relatively low-level transportation infrastructure such as general grade roads, which are an important support for the network effect of the entire regional transportation system.

\section{REFERENCES}

[1] Condeço-Melhorado A, Tillema T, de Jong T, et al. Distributive effects of new highway infrastructure in the Netherlands: the role of network effects and spatial spillovers[J]. Journal of Transport Geography, 2014, 34: 96-105.

[2] Chen Z, Haynes K E. Regional Impact of Public Transportation Infrastructure: A Spatial Panel Assessment of the U.S. Northeast Megaregion[J]. Economic Development Quarterly: The Journal of American Economic Revitalization, 2015, 29 (3) :519-520.

[3] Yan Hu, Wenxia Zhu. Spatial Spillover Effects of Transportation Infrastructure: Based on Regional Comparison of the Eastern, Central and Western Regions[J].Inquiry into Economic Issues, 2015(01):82-88. In Chinese

[4] Zhi Zhang, Hao Zhou. The Spillover Effect of Transportation Infrastructure and It's Industrial Difference - Comparative Analysis Based on Spatial Measurement[J].Journal of Finance and Economics, 2012, 38(03):124-134.In Chinese

[5] Holtz-Eakin, Douglas, and Amy Ellen Schwartz. "Spatial productivity spillovers from public infrastructure: evidence from state highways." International Tax and Public Finance 2.3 (1995): 459-468.

[6] Yu, Nannan, et al. "Spatial spillover effects of transport infrastructure: evidence from Chinese regions." Journal of Transport Geography 28 (2013): 56-66.In Chinese

[7] Álvarez-Ayuso, Inmaculada C., et al. "Integrating network analysis with the production function approach to study the spillover effects of transport infrastructure." Regional Studies 50.6 (2016): 996-1015.

[8] Cliff A D. Spatial autocorrelation[M]. London: Pion Publishers, 1973.

[9] L A. Spatial Econometrics: Methods and Models[M]. Dordrecht: Kluwer Academic Publishers, 1988.

[10] LeSage James R K P. Introduction to Spatial Econometrics[M]. Chapman and Hall/CRC, 2009.

[11] Elhorst J P. Specification and estimation of spatial panel data models[J]. INTERNATIONAL REGIONAL SCIENCE REVIEW, 2003, 26(3):244-268. 
[12] Binglian Liu, Peng Wu, Yuhai Liu. Transportation Infrastructure and China's Total Factor Productivity Growth: Spatial Panel Measurement
Analysis Based on Provincial Data[J].China Industrial Economics, 2010(03):54-64.In Chinese 